\title{
Research on University English Autonomous Learning Ability Based on
}

\section{Dynamic Systems Theory}

\author{
Zhang Rui \\ Luoyang Normal University,Luoyang,Henan 471022 China
}

\begin{abstract}
Dynamic system theory points out that internal elements and external system is closely related to, valuing the interaction between factors and variation. The English learners are classified into four groups, then research the characteristics of the best group learners. Characteristics is the affecting factor for autonomous learning ability. Only by fully understanding learners' own personality characteristics and take corresponding measures, can really improve the ability of English autonomous learning.
\end{abstract}

Key Words: Dynamic system theory; English Autonomous Learning Ability; variation

\section{INTRODUCTION}

Dynamic system theory considers that there is embeddedness and interactivity between each subsystem. Dynamic system theory opposes reductionism. The number of variables is not limited. Each individual differences and situational variability may become the moderator variables, which should not be ignored. The dynamic model provides a new perspective for retest of irregular theory assumes that individual data and the traditional theory can not explain the test. We should know what issues of two language development should pay attention to and the way to study these problems. The traditional model is static, linear and decisive, while the study on dynamic system theory model is dynamic, nonlinear and random.

The following gives the importance of dynamic system theory in the interpretation of two language development. One is about the variability, including free variability and system variability. The author puts forward the relatively high variability of the system of self reorganization, when the system is relatively stable and the variability is relative lower; system variability is a prelude to change and develop subsequently. The two is to emphasize the duration of a case study in language development, analyze individual pattern, pointed out it is important to understand the individual level variability and pattern when study the language development approaches, but the two language acquisition research as a group in unit pays attention to overall performance.

Language development is a continuous process, which is affected by a learner's internal and external difference. Dynamic system theory allows researchers to better observe the dynamic relationship between the relative variation. The nine characteristics of dynamic system theory are: 1.sensitive to the initial state 2.the interconnection 3.development of nonlinear 4 Being changing through internal restructuring and environmental interaction, including a chaotic variation and suction state temporary 7 . dynamic repeat 8 changes by the interaction between the internal restructuring and the environment change 9 float features.

We should study language as a whole by combining social and psychological linguistics perspective. Dynamic system theory points out that internal elements and external system is closely related to, valuing the interaction between factors and variation.

Larsen-freeman in 1997 took the lead in the Dynamic Systems Theory dynamic theory was 
introduced to the field of two language acquisition, but had not paid attention to. Until after 2005, two language acquisition research from the angle of dynamic system that had become the climate. This is embodied in the important international journals published related Album: Emergentism(special issue) of 2006 fourth period in Applied Linguistics , 2007 first period in Bilingualism, dynamic system theory monograph inThe Modern Language Journal of second period in 2008, complex adaptive system of Language Learning in 2009 (Complex Adaptive Systems) supplement. In addition, a major international conference in 2011 sixteenth session of the world academic as Applied Linguistics Conference also held a symposium, introduces the research status of dynamic system theory given by Larsen-freeman 、 Verspoor and De Bot at the meeting.

\section{System Overall Association}

Many language acquisition researcher consider learners' language development as a continuous gradient linear process, from zero to a near native level. In contrast, dynamic system theory consider that learning a second language is not a simple linear process, but a complex learning process on the basis of use. As a cognitive and social resources combination, complexity and creativity of language is to emerge from the interaction.

The theory of dynamic system composed of multiple variables or parameter forms. These variables are interconnected and in the transverse driving. The language learners themselves is a complex dynamic system and the involved variables including cognitive environment: such as learners' intelligence, memory, the mother Language, two language knowledge, learning motivation, self-efficacy, teaching environment, the social environment and the objective environment. Because of multi variable coupling interaction in various environments, multiple level, so the main features of dynamic system is with full connectivity of a variety of circumstances connected.

That dynamic system theory, with the long-term development system, subtle differences in initial conditions may be enlarged gradually, and eventually lead to great differences between systems. The system may also be subject to interference or repulsion huge and does not show any change and it appears from the perspective of dynamic system theory: the impact is an initial state. There are common in language learning. The personality characteristics self-confidence of learners is important to learn well.

The development of language is the state and the development process of absorbing states coexist, like a ball rolling on a plane of a rugged, rolling trend is forward, the ball through the route is tortuous, the plane of the pit is absorbing state, whereas projection is dismissed state. The force of gravity is absorbing state hinder the ball forward rolling sub. If there is a gust of wind blowing, can let the ball against the force of gravity acceleration scroll. This time the wind is a kind of control parameters. In foreign language learning, learner goals or more target balance between the targets determines his language learning behavior and learning process. Supposing the learning motivation hypothesis as a control parameter, it can attract learners from entertainment to focus on language learning. Learning motivation is a part of the emotional factors, in addition to the learner's confidence and character. Therefore, in teaching, teachers should pay more attention to the emotion of the learners.

Learner factors includes individual cognitive differences, individual differences and learning strategies of emotion. The dynamic interaction is difficult to separate from each other. He also advocated, future learner characteristics research should try to take a systematic approach to identify the cognition, emotion and motivation of the higher level of the combination. It is often used as a whole to play a role. Synthesis Learning Ability research is a good example.

\section{English Autonomous Learning Ability}

This research adopts the non random sampling method to select 155 test objects, they are English Class one or two of the third grade students. The survey used a 
questionnaire form, a professor of psychology at Peking University in view of gender role, China college students scale, and the ability of autonomous learning scale. The use of SPSS16.0/PC statistical software for survey data for Pearson 'S Correlation Test (Pearson correlation test), and Regression Correlation regression analysis, to infer data obtained are listed in table form, openness to experiment, operability. According to CSRI scale, the learners are divided into four types: androgyny, feminine, masculine and differentiation. This process is statistical process is very complex, in addition to the statistical data, need to divide the learners into four types, the statistics of each learner four indicators (M+, F+, M-, F-) of the median score. The use of statistical theory, the psychology theory, the application of language learning theory and cognitive theory of language, combined with the practice of English teaching to write a research report.

In the current English teaching situation, the new teaching mode are with modern information technology. Including the learner's attitude and motivation, learner strategies and learner factors such as environment and complex learning ability, these factors determine the degree of learner autonomy. Most research on China English learners individual differences from age, aptitude, cognitive style, attitude, motivation and personality of a few aspects of learners, a few scholars are involved in the empirical study. The following are the research: Research on domestic CSRI scale based on gender role of learning motivation and learning achievement (2008), the study of gender role and learning strategies: A Study on the relationship between English Major Students' gender role and English learning strategies of non University (2006), gender role on English major research yet, research on gender roles and English the ability of autonomous learning is not. According to the Chinese students CSRI scale, China students are divided into four types. Through the correlation and regression analysis to identify the specific factors affecting the ability of autonomous learning, this research way is difficult to do. In the teaching, according to different types of learners, to take targeted guidance mode, provides a feasible basis and guide for teachers to teach students in accordance with their aptitude. Teachers make students "language learning is guided by teachers" gradual transite to a "semi autonomous language learning" in the teaching, and finally achieve completely autonomous learning "". This study reports an empirical study of Chinese English major students, its purpose is to explore the Chinese English major students in English learning process and the possible relationship between the personality and the ability of autonomous learning.

Through the comparative analysis of the data, the author found that:

\subsection{Through the CSRI scale, there is a significant positive correlation between $\mathrm{M}+$ and the ability of autonomous learning.}

Autonomous learning ability and F- are having significantly negative correlation, the correlation between $\mathrm{F}+, \mathrm{M}$ - and the ability of autonomous learning related is not obvious. 3. Based on the $\mathrm{M}+, \mathrm{F}+, \mathrm{M}-$, draw the statistical analysis of F- main factor scores of feature words: in Chinese context, there is a significant correlation of learners who are short-sighted and weakness of the four personality characteristics and their English autonomous learning ability, and refuse to submit independent, 4. For M+, F+, M-, measuring the correlation between F- and the ability of self-regulated learning is the focus of this study. Regression of autonomous learning ability on the influence of personality characteristics of learners' analysis is the focus of this study.5. With the results of the analysis, concrete analysis of each kind of personality characteristics of the self-regulated learning ability is to influence the learners of English. The analysis process requires relevant research results combined with psychology, is also the subject of a major difficulty. Finally, the analysis results at home and abroad through the other theoretical and experimental method for the consistent results fully proved the feasibility of the study. 
Involves a lot of statistical data in the process, the CSRI scale has 100 items, each are with data, through a certain formula to remove invalid data, by calculating the median can be divided into four types, finally, correlation and regression analysis of statistical method involve a very professional statistics, with the final analysis combining psychological theory is analyzed, both require a lot of time, also need to test accurately, scientific and objectively.

\subsection{The Problems Existing in University English Autonomous Learning Ability}

The formation is influenced by many factors of students' autonomy, in addition to attention, effort and school teacher training degree, but also influenced by the students of school environment, the external teaching condition and traditional teaching concept. The concrete is mainly reflected in the following aspects:

3.2.1 The absolute authority of the teachers leads to lack of consciousness of students' Autonomous Learning

The formation is influenced by many factors of students' autonomy, in addition to attention and effort and school teacher training degree, students own consciousness is closely related to, but also influenced by the students of school environment, the external teaching condition and traditional teaching concept. But when it comes down to it, the concrete is mainly reflected in the following aspects:

In traditional English teaching, the teacher is the guide, play a leading role in the teaching and be in charge of the class. The behavior of students affected greatly by teachers, teachers are the models and the source of knowledge .The teachers constantly learning and constantly correct the errors committed by students in language. As the leading role of education, teachers are with strong authority, which originated from the traditional mode of education, which has been Chinese inheritance. China students were taught to accept the cramming method of teaching, passively accept all kinds of knowledge, lack of independent thinking ability and innovation consciousness. Secondly, China traditional culture of "the teacher's dignity" ideological shackles the cultivation of critical spirit of students. Teachers are in the absolute position of authority. Even if the students have different ideas, and they were devoid of. Teachers are of this cultural "hegemony".

\subsubsection{The lack of real conditions of using the foreign language leads to the lack of learning motivation.}

Widdowson once pointed out: "the language learning has two aspects, understand and do, namely the ability and behavior. The method of structure we're talking about, those activities require different skills training is to help consolidate their knowledge of the language, these are used to help language learning measures. Do from belong to understand, however, the task of language usually is used for practice purposes, you won't be around to speak some of the sentence, or to be more familiar with certain kinds of sentence structure to read some essays. In ordinary language, usually in activities involving language, we always have some help to achieve the language used by the purpose. "Understand belong to do (Widdowson, 1990:157), the final purpose of learning a foreign language is to communicate with foreign language, "do" is to use foreign language to achieve communicative purpose.

3.2.3 Because of restrictions of the assessment content, students' Autonomous Learning Space are limited.

Now, college students have many courses, free time is limited, plus a variety of school rules limit, students seldom have time to develop autonomous learning ability by self-study. Moreover, the traditional test method exists, also make the students may not be truly learning independently. The traditional test methods encourage students to consider the scope of the examination for the entire content of learning, and the examination results is one of the main learning motivation, closely connected with the enthusiasm of students. But the scope of this kind of exam is often very limited, it reflects only one part of the students knowledge of English, can not reflect the real use of language. Guided by the examination baton, students could not or would not carry out 
autonomous learning, the communicative competence will weaken, and the motivation to learn is with strong utilitarian.

\subsubsection{The school teaching conditions are difficult to meet the needs of students' autonomous learning.}

Students' autonomy in addition to being subject to the learner internal factors, but also depends on its external environment: school teaching condition. Here the teaching conditions include two aspects: one is such as computer, multimedia, network construction and hard conditions. The number of these teaching equipment should match the number of College students. The lack of teaching hardware condition to a great extent restricted the students desire to learn and learning efficiency. The two is mainly based on teachers software facilities. Our country university foreign language teachers are mainly domestic university cultivate local talent,their English level is difficult to achieve the level of native English speaker. Coupled with the rapid increase of the number of students, the heavy task of teaching, teachers' professional level and teaching ability can not improve correspondingly. In addition, teachers must have the ability to use modern information technology, multimedia technology and network technology.

\subsubsection{Personality Factors}

Many people believe that the outgoing, competitive and adventurous spirit of the students than the introverted, shy and reticent students are good at language learning. But many researchers don't support the result. In addition, a person's character may also be affected by the external culture, its social position and the current environment and some other factors need to be changed. Therefore, referring to what kind of character to achieve language learning, it is very difficult to sum up in a word. However. Teachers should actively find and meet the various needs of students in terms of personality, to create a suitable or to challenge the different characters of the learner's learning environment for the students of different character, providing learning opportunities balanced. At the same time, teachers should also have good qualities. This can in a positive way influence the students to create a good classroom atmosphere.

\section{Measures to improve autonomous learning capability on the basis of the dynamic system theory.}

English learning is a continuous process, affected by a learner's internal and external difference. English autonomous learning ability by learning all kinds of factors inside and outside the influence of various factors, internal and external interaction, learners' internal factors and environment produce interaction, learning effect will be getting better and better. Dynamic system theory point of view allows researchers to better observe the dynamic relationship between the relative variation. This study uses the psychology scale, CSCI scale conducted by Qian Mingyi. The English learners are classified into four groups, then research the chareteristics of the best group learners.

\subsection{Create a suitable learning environment.}

Teachers can create a good learning environment for students in the classroom in addition, in the University, the students have a vast expanse of extracurricular time for independent study, first of all, need autonomous learning extracurricular environment, for example, the construction of the autonomous English learning system network, a good professional learning atmosphere, including extracurricular practice activities: English lectures, oral English contest. Dubbing Contest, translation contest. Held a variety of extracurricular activities: a variety of language and culture festival. With the rapid development of information technology and network technology, making full use of information technology and network resources can not only be a supplement to the teaching of College English, greatly broaden the students' English learning channels, but also promote students' learning style change. To organize various extracurricular real to create a harmonious classroom environment is the key of students' Autonomous learning. Rodgers thinks, the creativity of a person only when he feels "psychological safety" and 
"mental freedom" condition, in order to obtain the maximum performance and development. Therefore, teachers should adjust the role, the students become the information provider, facilitator, student learning guide,Teachers can use modern educational technology, develop and utilize English teaching resources, can greatly improve the efficiency of student learning. When conditions permit, teachers should make full use of auditory and visual means, such as: pictures, audio etc. various, rich in content and form of teaching, promote students' classroom learning; to use computer and multimedia teaching software; exploring new teaching mode; promoting students' individualized learning; developing and using radio and television, newspaper English network, library and various resources to create conditions for students' Autonomous learning.

Whether to have the ability of autonomic learning in relation to the survival and development of a person. Therefore, University English teaching should be through the conscious cultivation of students ability of English autonomous learning, make them "be guided by language learning" a gradual transition to a "semi autonomous language learning", and finally to "full autonomy learning".

\subsection{Form good English learning habits.}

Learning a foreign language should speak more: read English more and speak English more. However, quite a few students are reluctant to speak a foreign language and can't speak a foreign language. But, speaking English is so important to improve the ability of learning English. So it is necessary to establish the habit of speaking English, repeat beautiful English, when deeply love English, the learner is willing to speak English, so the establishment of long-term habit can improve the quality of. In addition, learning foreign languages should also listen, listen to the beautiful sound recording, listen to the native English and feel the authentic English accent.

\subsection{To stimulate students interest in learning English.}

The students' autonomous learning will depend on the degree of their motivation and confidence, knowledge and skills. Awareness and motivation are two important constructing factors of autonomous learning. As there is no awareness and motivation, to cultivate the ability to talk is in vain. Therefore, teachers should attach importance to cultivation of students' autonomous learning awareness and motivation. English learning motivation is the direct promotion of an internal motivation of English learning, is a kind of initiative and enthusiasm of the language learners' mental state. In the process of teaching, teachers should love, according to the interest of students life experience, ability range, intelligent factors, cognitive ability, by the results of the actions to strengthen the learning motivation, and gives reward or punishment performance to external behavior.

\subsection{Take part in social practice activities}

Take part in social practice activities, such as students can serve as the English tour guide, knows the application scene of their English learning through practice, in the Multi-National Corporation, know how to use English and when to use English in practical work and kno what extent can freely deal with the needs of the work.

\subsection{Learning Strategy Training.}

Language learning between training and self learning strategy is a relationship between means and purposes. Learning strategy training is conducive not only to improve the learning effect, to better achieve the learning objectives, but also conducive to the students to explore the suitable learning way, enhance their ability of independent learning and autonomous learning. The study found that, the ideal language learner has the following seven characteristics: 1) willing to guess, and the guesses is correct; 2) having strong communication power, and willing to learn in communication; 3 ) there is no sense of psychological inhibition; 4) Be willing pay attention to the language form while communicating; 5) to practice and practice; 6) listen to what others say; 7) attention to the meaning expression .

The cultivation of English autonomous learning ability is by the training of cognitive strategies and 
metacognitive strategy training. The training of cognitive strategies can make students understand and master the skills of various learning strategies, such as: listening skills, communication strategies, reading strategies, writing skills, translation skills and problem solving skills; The training of meta cognitive strategy, can enable students to develop study plans, select learning methods, monitor learning tasks, learning arrange the assessment process, the completion of a task habits, the learner become independent step by step, has gradually become a real sense of "autonomous language learners".

\subsection{The cultivation of students' English learning state.}

When the true happiness a person physically and mentally, you will say, so first of all let students like English, understand English culture, then understand the habit of thinking in English, to understand the human geography of the English speaking countries. If the students feel it is boring, and they don't want to speak English. English speaking state should be at ease, as it is also consistent with the character of western.

\section{Conclusions}

Role of the learners in autonomous learning are in large unremittingly. That is to say, those who are not easy to be a setback and unremittingly learners than those who are easy to suffer a setback in the learners more easily to obtain good results in the autonomous learning ability. Those learners have great courage are more easily than those easily discouraged learners in autonomous learning success. Therefore, this investigation shows that compared with the persistence characteristics of learners have the advantage that learners tend to give up the autonomous learning, so teachers should pay attention to the cultivation of students' persistence in the classroom and extracurricular trait. Learner independence degree has obvious effect on autonomous learning independent.

Learners have advantages over the lack of independence of the learner. Students need to complete an independent learning process, so the process of autonomous learning is completely different from the teacher centered learning. Independent learners show advantages in thinking and reasoning. They can set appropriate learning objectives, selection and use of effective learning strategies to achieve this goal, and can identify and select the relevant resources and support. So the most strongly independent learners are easier to success than the lack of independence of the learners in autonomous learning. Learners with short-sighted feature have a negative impact on the autonomous learning ability. Their autonomous learning ability is not strong. They were careless, not considered comprehensive and unrealistic. They can't plan the whole learning process well, have no long-term planning, and did not recognize the English skills is the foundation for the study of the professional knowledge. Vulnerability has negative effect on the ability of autonomous learning. The fragile and sensitive learners are easily to react to others sensitively, which affects their English learning. Androgyny learners have more feminine features and positive masculine characteristics of learners. They are persevering, can overcome various difficulties and cope with all kinds of pressure. They can do their best to achieve their learning goals, according to the advantages and disadvantages of selection of effective learning strategies, obviously, these two characteristics play an important role in autonomous learning. Undifferentiated learning refers to those who have more negative masculine characteristics and feminine characteristics, positive masculine and feminine characteristics. They are not independent and not very good to choose the correct learning strategies or evaluate their learning process. They have a weak personality, deeply influenced under pressure, are easily to change their attitude and idea. They are short-sighted, pursuit short-term success, and have a negative effect on their autonomous learning. Overcome various difficulties and deal with all kinds of pressure, they can do their best to achieve their learning goals, they can choose effective learning strategies according to their own strengths advantages and disadvantages. Male learners with more positive masculine features and less positive feminine features of 
learners have the advantage of their independence in autonomous learning. They can help to evaluate the learning process, tend to give up, being lack of willpower, can complete the learning process of informal, and are short-sighted and self-centered. Their autonomous learning ability is not strong. Female learners have more positive feminine features and less positive masculine characteristics of learners. They unremittingly can help them to have the will to achieve learning goals, their fragile, short-sighted, easier to change your mind and attitude under pressure. They rely on the teacher more, so they are not the best learners.

This study shows that androgyny learners is the best learners, teachers should try their best to help students become androgynous learners. Students should make the greatest efforts to make decisions in autonomous learning, establish realistic goals with the help of the teacher's goal. They should often carry out self management and self assessment, and perform their own learning process. They should be masters of their own learning and be responsible for their own learning,

Of course, this does not mean that the students would be completely out of the teacher's help. Teachers should help female learners be competitive in autonomous learning, believe that students have the ability to control their own learning, help students establish the consciousness of independent learning, build the actual learning goals, choose a suitable learning content including long-term learning and short-term goals and study plan. They should help learners do self assessment and acquire some skills: control the learning process, self management, help them choose the learning mode and take appropriate learning strategies. In order to help learners be competitive in autonomous learning, teachers should adopt the various methods of learning strategies, because they are relatively weak in the use of learning strategies weak. Strategy training idea is compelling: "because it provides a method to help ordinary learners become autonomous." Teachers should introduce learning strategies to students, let the male learners understand their reason for applying these learning strategies. Intrinsic motivation that can stimulate their learning strategy use. Then the students will be more interested in the use of strategies. Their learning strategy will be greatly improved. One approach that can help learners is: through the establishment of century goal, guide the student to evaluate their learning process, help students understand how to use cognitive strategy cognitive.

We should encourage the undifferentiated learners to learn more in English autonomous learning environment. To some extent, one of the important factors to develop students' independent learning ability is to give students in the cooperative learning environment the opportunity to decide. Therefore, the development of a pleasant environment of independent study of students autonomous learning ability is very necessary. In this environment, students have more chance to control the learning content and learning strategies, in class activities, will interact with the opportunity to use the target language. To establish the good outside of the classroom learning environment is very important: the reading room, online learning room, English corner, English Salon and English competition, all of these can provide students with their learning opportunity. In addition, the establishment of autonomous language learning center is the perfect way to develop students' autonomous learning ability. In short, to create a good environment for autonomous learning will enhance the students' autonomous learning motivation, so that they become more willing to do English autonomous learning.

\section{Reference:}

[1]. Allwright, D. 1988. Individualization and Autonomy in Language Learning. ELT Documents 131.Modern English Publications and the British Council.

[2]. De Bot K, Lowie W \& Verspoor M. Dynamic Systems Theory approach to second Language Acquisition [J] Bilingualism, 2007, 109(1) 7-21 
[3]. Glasersfeld E.V. Radical constructivism [M]. London: Routledge Falmer, 2002. 12-18 4. Greenberg K.H. The cognitive enrichment advantage teacher handbook $[\mathrm{M}]$. Chicago: KCD Harris \& Associates Press,2005. 35-48

[4]. Holec H. Autonomy and Foreign Language Learning $[\mathrm{M}]$. Oxford: Pergamon Press, 1981.3

[5]. Li Lanxia, Dynamic System Theory and Second Language Development [ J ] Foreign Language Teaching and Research, 2011(3), 409-421。

[6]. Little D. Learner Autonomy: Definitions,
Issues and Problems $[\mathrm{M}]$. Dublin: Authentic, 1991. 4-12

8. Nunan D. Closing the Gap Between Learning and Instruction $[\mathrm{M}]$. TESOL Quarterly, 1995. 133-158

[7]. 9. Thelen E \& Smith L. A Dynamic Systems Approach to the Development of Cognition and Action [M] Cambridge, MA: MIT Press, 1994

[8]. 10. Song Hong, The chaos theory to the explanation power of second language acquisition [J] China Foreign Language, 2009(6) 66-69 